\title{
Cervical Cancer Patient-Derived Orthotopic Xenograft (PDOX) Is Sensitive to Cisplatinum and Resistant to Nab-paclitaxel
}

\author{
TAKASHI MURAKAMI ${ }^{1,2,3}$, TAKUYA MURATA ${ }^{4}$, KEI KAWAGUCHI ${ }^{1,2,5}$, \\ TASUKU KIYUNA ${ }^{1,2,6}$, KENTARO IGARASHI ${ }^{1,2,7}$, HO KYOUNG HWANG ${ }^{1,2,8}$, \\ YUKIHIKO HIROSHIMA ${ }^{3}$, CHIHIRO HOZUMI ${ }^{9}$, SHIN KOMATSU ${ }^{9}$, TAKASHI KIKUCHI ${ }^{9}$, \\ THINZAR M. LWIN ${ }^{2}$, JONATHAN C. DELONG ${ }^{2}$, KENTARO MIYAKE $^{1,2,3}$, YONG ZHANG ${ }^{1}$, \\ KUNIYA TANAKA ${ }^{3}$, MICHAEL BOUVET $^{2}$, ITARU ENDO $^{3}$ and ROBERT M. HOFFMAN ${ }^{1,2}$ \\ ${ }^{1}$ AntiCancer, Inc., San Diego, CA, U.S.A.; \\ ${ }^{2}$ Department of Surgery, University of California, San Diego, CA, U.S.A.; \\ ${ }^{3}$ Graduate School of Medicine, Yokohama City University, Yokohama, Japan; \\ ${ }^{4}$ Department of Obstetrics and Gynecology, Kawasaki Medical School, Okayama, Japan; \\ ${ }^{5}$ Department of Surgery, Graduate School of Medicine, Tohoku University, Sendai, Japan; \\ ${ }^{6}$ Department of Orthopedic Surgery, University of the Ryukyus, Okinawa, Japan; \\ ${ }^{7}$ Department of Orthopedic Surgery, Kanazawa University, School of Medicine, Kanazawa, Japan; \\ ${ }^{8}$ Department of Surgery, Division of Hepatobiliary and Pancreas Surgery, Severance Hospital, \\ Yonsei University College of Medicine, Seoul, Republic of Korea; \\ ${ }^{9}$ AntiCancer Japan Inc., Tokyo, Japan
}

\begin{abstract}
Background: Cervical cancer is a world-wide problem that requires transformative therapeutic strategies. We have previously developed patient-derived orthotopic xenograft (PDOX) nude-mouse models of this disease. In the present report, we demonstrate that the standard drug, cisplatinum $(C D D P)$, is highly-effective while the new, highly-touted agent, nab-paclitaxel (NAB-PTX) is ineffective. Materials and Methods: Cervical PDOX tumors were grown on the cervix of nude mice for 4 weeks after surgical orthotopic implantation (SOI). Tumors were treated with CDDP or NAB-PTX. Results: $H \& E$ staining demonstrated that the PDOX tumor recapitulated the original patient tumor. CDDP was highly-effective. One tumor that was treated with $C D D P$ completely regressed. CDDP-treated tumors were smaller (tumor volume ratio: $0.42 \pm 0.36$ ) than
\end{abstract}

This article is freely accessible online.

Correspondence to: Takuya Murata, M.D., Kawasaki Medical School, Department of Obstetrics and Gynecology, 577, Matsushima, Kurashiki-city, Okayama, 701-0192, Japan. Tel: +81 864621111, e-mail: t.muratactac@gmail.com; Robert M. Hoffman, Ph.D., AntiCancer, Inc., 7917 Ostrow Street, San Diego, California 92111, U.S.A. Tel: +1 8586542555, Fax: +1 8582684175, e-mail: all@anticancer.com

Key Words: Cervical cancer, patient-derived othotopic xenograft, PDOX, nude mice, drug response, cispatinum, nab-paclitaxel. the control group (tumor volume ratio: $3.47 \pm 1.66)(p<0.01)$. In contrast, NAB-PTX did not show significant efficacy on the cervical cancer PDOX model (tumor volume ratio: $2.85 \pm 1.45)(p=0.47)$. CDDP-treated tumor weight $(50 \pm 50$ $\mathrm{mg})$ was significantly less than control $(238 \pm 114 \mathrm{mg})$ $(p<0.01)$. NAB-PTX-treated tumors were not reduced in weight $(246 \pm 136 \mathrm{mg})$ compared to control $(p=0.91)$. There were no significant differences in mouse body weight between groups. Histological evaluation demonstrated that CDDP-treated tumors were fibrotic with scattered squamous cell nests compared to control or NAB-PTX-treated tumors. Conclusion: The results of the present study demonstrate the power of PDOX models of cervical cancer to distinguish efficacy of potential therapeutics for individual patients with this disease.

Cervical cancer is the second-most common cancer worldwide in women. The majority is classified as squamous-cell carcinoma (SCC). SCC resulted in 454,000 cases and 200,000 deaths in 2010 (1). Chemotherapy drugs used for cervical cancer include nanoparticle albumin-bound (nab)-paclitaxel (NAB-PTX), carboplatinum, cisplatinum (CDDP), bleomycin, mitomycin-C, vincristine, and irinotecan (2). Retinoids and interferon in combination with cytotoxic chemotherapy have been shown to be effective for SCC (3). However, there is no standard treatment for metastatic cervical cancer.

Clinically-relevant mouse models of cancer can be used for tailor-made therapy based on the patient-derived tumor. 
Our laboratory pioneered the patient-derived orthotopic xenograft (PDOX) nude mouse model with the technique of surgical orthotopic implantation (SOI), including pancreatic (4-7), breast (8), ovarian (9), lung (10), cervical (11), colon (12-14), stomach (15), sarcoma (16-20) and melanoma (21).

We have previously developed mouse models of patient cervical cancer. Tumors in nude mice had histological structures similar to the original tumor and were stained by anti-HER2 antibody in the same pattern as the patient's cancer. In the PDOX model of HER2-positive cervical cancer, carboplatinum was active. However, the most active regimen was the combination of tumor-targeting Salmonella typhimurium A1-R and trastuzumab (22).

Recently, patient-derived xenograft cervical cancer mouse models were also described where the aggressiveness of the patient tumor was replicated in mouse models (23). NABPTX is paclitaxel linked to albumin nanoparticles, which makes it soluble. The development of nanotechnology as a delivery system for NAB-PTX has improved the pharmacokinetics and pharmacodynamics of paclitaxel, in part by decreasing its hydrophobicity (24). In the present study, we compared the efficacy of two drugs for cervical cancer, CDDP and NAB-PTX in a cervical-cancer PDOX model.

\section{Materials and Methods}

Animals. Female athymic (nu/nu) nude mice (AntiCancer, Inc., San Diego, CA, USA), 4-6 weeks old, were used in this study. Mice were kept in a barrier facility under HEPA filtration. Mice were fed with an autoclaved laboratory rodent diet. All mouse surgical procedures and imaging were performed with the animals anesthetized by intramuscular injection of a $0.02 \mathrm{ml}$ solution of $50 \%$ ketamine, $38 \%$ xylazine, and $12 \%$ acepromazine maleate. All animal studies were conducted with an AntiCancer Institutional Animal Care and Use Committee (IACUC)-protocol specifically approved for this study and in accordance with the principals and procedures outlined in the National Institute of Health Guide for the Care and Use of Animals under Assurance Number A3873-1 (11).

Specimen collection. The patient provided written informed consent and the tumor specimen was procured under the approval of the Institutional Review Board of Kawasaki Medical School.

Patient characteristics. The patient was a 57-year-old female with primary cervical cancer. Histology demonstrated squamous cell carcinoma (grade 2) (Figure 1C). The patient received no previous treatment. A radical hysterectomy was performed with bilateral salpingo-oophorectomy and pelvic lymphadenectomy.

Establishment of a cervical cancer PDOX model with surgical orthotopic implantation (SOI). A fresh resected primary tumor was obtained and transported immediately to the laboratory on ice. The specimen was cut into $5 \mathrm{~mm}$ fragments, which were implanted subcutaneously to nude mice. Three months later, implanted tumors grew to more than $10 \mathrm{~mm}$ in diameter. The established tumors were cut into $4 \mathrm{~mm}^{3}$ fragments. After anethesizing mice, a $7 \mathrm{~mm}$ lower abdominal midline incision was made, and then the uterine cervix was exposed. A single fragment was implanted in the cervix of each mouse using 8-0 nylon sutures (Ethilon, Ethicon, Inc., NJ, USA). The wound was closed with 6-0 nylon sutures (Ethilon, Ethicon, Inc., NJ, USA).

Treatment study design in the PDOX model of cervical cancer. Treatment protocol. G1: control group treated with vehicle (i.v., phosphate buffered saline (PBS), once a week, 3 weeks, n=7); G2: test group treated with CDDP (i.v., $5 \mathrm{mg} / \mathrm{kg}$, once a week, 3 weeks, $\mathrm{n}=7$ ); G3: test group treated with NAB-PTX (i.v., $10 \mathrm{mg} / \mathrm{kg}$, twice a week, 3 weeks, $n=7$ ). Treatment started four weeks after orthotopic implantation. Mice were sacrificed on day 22, then tumors were resected for further evaluation. Tumor length and width were measured both on day 0 and day 22. Tumor volume was calculated with the following formula: Tumor volume $\left(\mathrm{mm}^{3}\right)=$ length $(\mathrm{mm}) \times$ width $(\mathrm{mm}) \times$ width $(\mathrm{mm}) \times 1 / 2$. Tumor volume ratio was defined as the ratio of volume on day 22 to day 0 .

Tumor tissue was removed with surrounding normal tissues at the time of resection. The tissues were fixed in $10 \%$ formalin and embedded in paraffin before sectioning and staining. Tissue sections $(3 \mu \mathrm{m})$ were deparaffinized in xylene and rehydrated in an ethanol series. PDOX tumors were also evaluated with frozen section. Tumors were divided into 2-3 mm fragments, then embeded in Neg50 Frozen Section Medium (Thermo Fisher Scientific, Waltham, MA). The embedded tissues were immediately frozen with liquid nitrogen. Tissue sections $(8 \mu \mathrm{m})$ were made with a cryostat. Hematoxylin and eosin (H\&E) staining was performed according to standard protocols and examined using an $\mathrm{BH}-2$ microscope (Olympus Corporation, Japan) equipped with a INFINITY1 2.0 megapixel CMOS digital camera (Lumenera Corporation, Canada). All images were acquired using INFINITY ANALYZE software (Lumenera Corporation) without post-acquisition processing (11).

Statistical analysis. SPSS statistics version 21.0 was used for all statistical analyses (IBM, New York, NY, USA). Significant differences for continuous variables were determined using the Student's $t$-test. Data are presented as average \pm SD. Bar graphs expressed average, and error bars show SD. A probability value of $\mathrm{P}<0.05$ was considered statistically significant.

\section{Results}

Cervical PDOX tumors were grown on the cervix of nude mice for 4 weeks after SOI (Figure 1A). H\&E demonstrated that the PDOX tumors recapitulated the original patient tumor (Figure 1B, C). CDDP was highly-effective on the cervical cancer PDOX. One tumor treated with CDDP completely regressed. CDDP-treated tumors were significantly smaller (tumor-volume ratio: $0.42 \pm 0.36$ ) than control-group tumor (tumor volume-ratio $3.47 \pm 1.66$ ) $(p<0.01)$ (Figure 2A). In contrast, NAB-PTX did not have efficacy on the cervical-cancer PDOX model (tumor volume ratio: $2.8 \pm 1.45)(p=0.47)$. CDDP-treated tumor weight $(50 \pm 50 \mathrm{mg})$ was significantly less than control $(238 \pm 114 \mathrm{mg})$ $(p<0.01)$ (Figure 2B). NAB-PTX-treated tumors were not reduced in weight $(246 \pm 136 \mathrm{mg})$ compared to control $(p=0.91)$. There were no significant differences in mouse body weight among groups (Figure 2C). Histological 

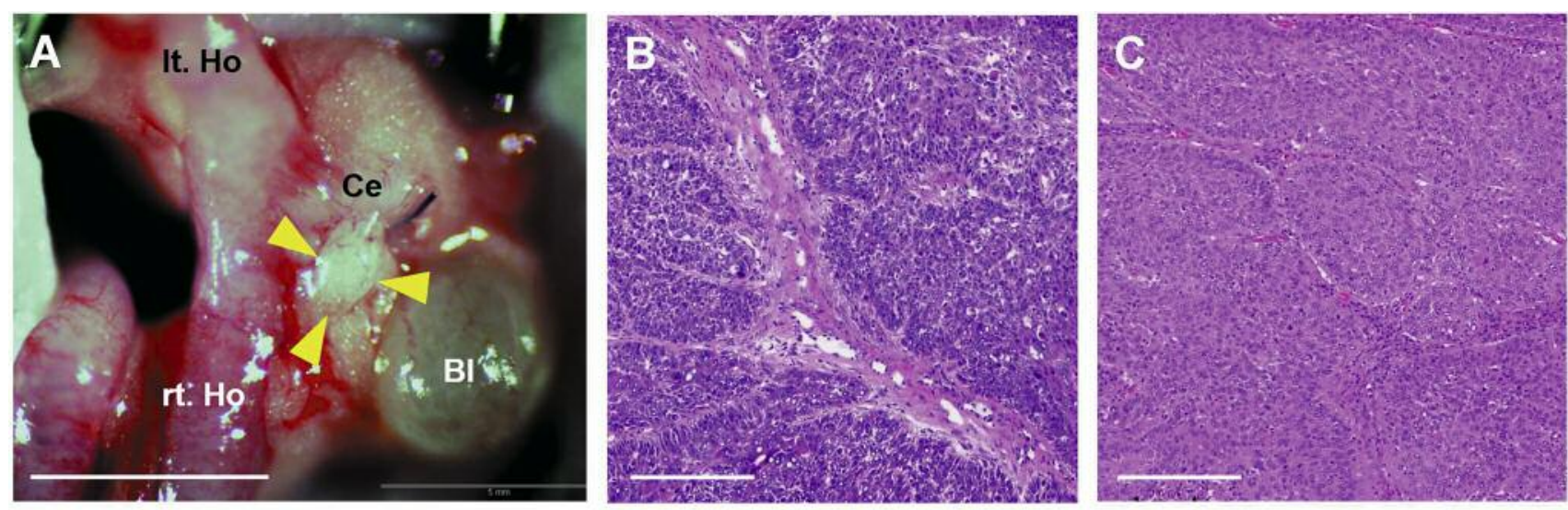

Figure 1. Cervical-cancer patient-derived orthotopic xenograft (PDOX) (A) PDOX tumor was grown on the cervix four weeks after surgical orthotopic implantation (SOI). Arrowheads indicate the PDOX cervical tumor; rt. Ho, right uterine horn; lt. Ho, left uterine horn; Ce, uterine cervix; Bl, urinary bladder; scale bar, $5 \mathrm{~mm}(B) H \& E$ staining of a PDOX tumor in the control group; scale bar, $200 \mu \mathrm{m}(C) H \& E$ staining of patient's original tumor; scale bar, $200 \mu \mathrm{m}$.

A
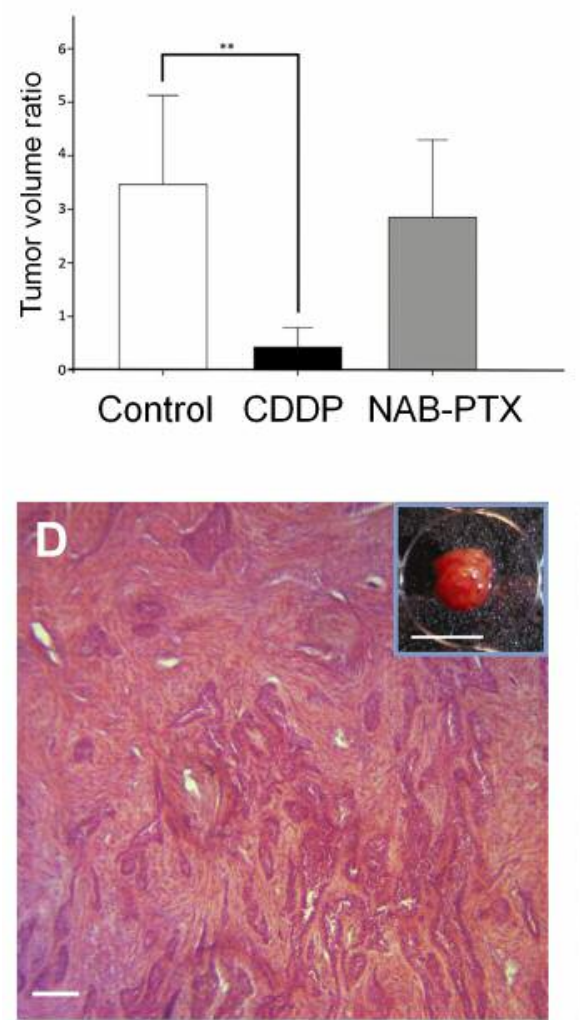

B
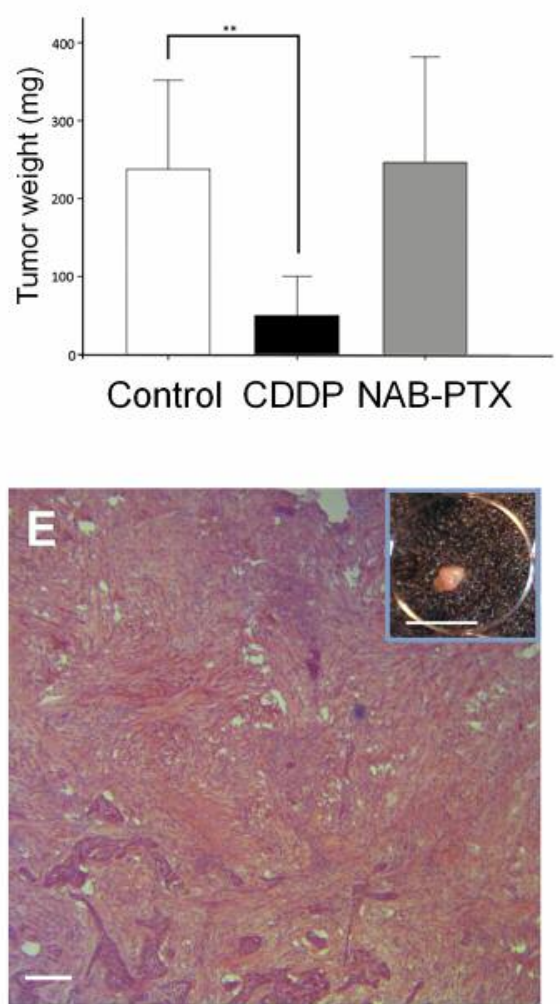

C
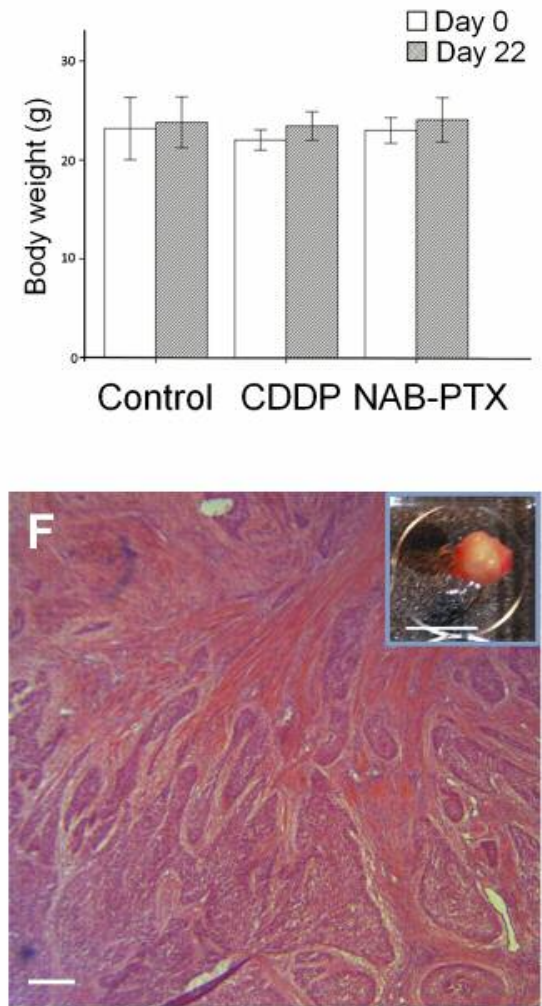

Figure 2. Treatment efficacy of chemotherapeutic drugs in a cervical cancer PDOX model (A) Bar graph shows tumor volume ratio that was defined as the ratio of volume on day 22 to day 0. (B) Bar graph shows tumor weight on day 22. (C) Mouse body weight did not differ, both at the start and end of the study. Resected specimens and their H\&E-stained histology in control $(D), C D D P(E)$ and NAB-PTX $(F)$ groups. Two asterisks indicate p-value <0.01; error bars: \pm 1 SD; scale bars, $10 \mathrm{~mm}$ for specimens inserts, 200 um for histology (panels D-F); CDDP, cisplatinum; NABPTX, nab-paclitaxel. 
evaluation demonstrated that CDDP-treated tumors were fibrotic with scattered squamous-cell nests compared to control or NAB-PTX-treated tumors (Figures 2D-F).

The result of the present study is of particular importance, as it demonstrates the high efficacy on the PDOX model of a low-price generic drug, CDDP, and lack of efficacy of a high-cost patented drug, NAB-PTX.

\section{Discussion}

Our present and previous results $(11,22)$ together with the results of Rofstad et al. (23) indicate the potential important clinical use of patient-derived models in order to individualize and optimize treatment of this, often recalcitrant, disease. The results in the present show that an improvement on best-guess treatment could be achieved with the use of patient-derived models.

\section{Dedication}

This paper is dedicated to the memory of A.R. Moossa, M.D. and Sun Lee, M.D.

\section{Funding}

JSPS KAKENHI grant numbers 26830081 to $\mathrm{YH}, 26462070$ to IE and 24592009 to KT. The funders had no role in study design, data collection and analysis, decision to publish, or preparation of the manuscript.

\section{References}

1 Wang CW, Wu TI, Yu CT, Wu YC, Teng YH, Chin SY, Lai CH and Chen TC: Usefulness of p16 for differentiating primary pulmonary squamous cell carcinoma from cervical squamous cell carcinoma metastatic to the lung. Am J Clin Pathol 131: 715-722, 2009.

2 Hashimoto K, Yonemori K, Katsumata N, Hirakawa A, Hirata T, Yamamoto H, Shimizu C, Tamura K, Ando M and Fujiwara Y: Use of squamous cell carcinoma antigen as a biomarker of chemotherapy response in patients with metastatic cervical carcinoma. Eur J Obstet Gynecol Reprod Biol 159: 394-398, 2011.

3 Braud AC, Gonzague L, Bertucci F, Genre D, Camerlo J, Gravis G, Goncalves A, Moutardier V, Viret F, Maraninchi D and Viens P: Retinoids, cisplatin and interferon-alpha in recurrent or metastatic cervical squamous cell carcinoma: clinical results of 2 phase II trials. Eur Cytokine Netw 13: 115-120, 2002.

4 Fu X, Guadagni F and Hoffman RM: A metastatic nude-mouse model of human pancreatic cancer constructed orthotopically with histologically intact patient specimens. Proc Natl Acad Sci USA 89: 5645-5649, 1992.

5 Hiroshima Y, Maawy A, Zhang Y, Murakami T, Momiyama M, Mori R, Matsuyama R, Katz MH, Fleming JB, Chishima T, Tanaka K, Ichikawa Y, Endo I, Hoffman RM and Bouvet M: Metastatic recurrence in a pancreatic cancer patient derived orthotopic xenograft (PDOX) nude mouse model is inhibited by neoadjuvant chemotherapy in combination with fluorescenceguided surgery with an anti-CA 19-9-conjugated fluorophore. PLOS ONE 9: e114310, 2014.
6 Hiroshima Y, Zhang Y, Murakami T, Maawy AA, Miwa S, Yamamoto M, Yano S, Sato S, Momiyama M, Mori R, Matsuyama R, Chishima T, Tanaka K, Ichikawa Y, Bouvet M, Endo I, Zhao M and Hoffman RM: Efficacy of tumor-targeting Salmonella typhimurium A1-R in combination with antiangiogenesis therapy on a pancreatic cancer patient-derived orthotopic xenograph (PDOX) and cell line mouse models. Oncotarget 5: 12346-12357, 2014.

7 Hiroshima Y, Maawy AA, Katz MH, Fleming JB, Bouvet M, Endo I and Hoffman RM: Selective efficacy of zoledronic acid on metastasis in a patient-derived orthotopic xenograph (PDOX) nude-mouse model of human pancreatic cancer. J Surg Oncol 111: 311-315, 2015.

8 Fu X, Le P and Hoffman RM: A metastatic-orthotopic transplant nude-mouse model of human patient breast cancer. Anticancer Res 13: 901-904, 1993.

9 Fu X and Hoffman RM: Human ovarian carcinoma metastatic models constructed in nude mice by orthotopic transplantation of histologically-intact patient specimens. Anticancer Res 13: 283-286, 1993.

10 Wang X, Fu X and Hoffman RM: A new patient-like metastatic model of human lung cancer constructed orthotopically with intact tissue via thoracotomy in immunodeficient mice. Int $\mathrm{J}$ Cancer 51: 992-995, 1992.

11 Hiroshima Y, Zhang Y, Zhang M, Maawy A, Mii S, Yamamoto M, Uehara F, Miwa S, Yano S, Murakami T, Momiyama M, Chishima T, Tanaka K, Ichikawa Y, Bouvet M, Murata T, Endo I and Hoffman RM: Establishment of a patient-derived orthotopic xenograph (PDOX) model of HER-2-positive cervical cancer expressing the clinical metastatic pattern. PLOS ONE 10: e0117417, 2015.

$12 \mathrm{Fu}$ X, Besterman JM, Monosov A and Hoffman RM: Models of human metastatic colon cancer in nude mice orthotopically constructed by using histologically intact patient specimens. Proc Natl Acad Sci USA 88: 9345-9349, 1991.

13 Metildi CA, Kaushal S, Luiken GA, Talamini MA, Hoffman RM and Bouvet $\mathrm{M}$ : Fluorescently-labeled chimeric anti-CEA antibody improves detection and resection of human colon cancer in a patient-derived orthotopic xenograft (PDOX) nude mouse model. J Surg Oncol 109: 451-458, 2014

14 Hiroshima Y, Maawy A, Metildi CA, Zhang Y, Uehara F, Miwa S, Yano S, Sato S, Murakami T, Momiyama M, Chishima T, Tanaka K, Bouvet M, Endo I and Hoffman RM: Successful fluorescence-guided surgery on human colon cancer patientderived orthotopic xenograft mouse models using a fluorophoreconjugated anti-CEA antibody and a portable imaging system. J Laparoendosc Adv Surg Tech A 24: 241-247, 2014.

15 Furukawa T, Kubota T, Watanabe M, Kitajima M, Fu X and Hoffman RM: Orthotopic transplantation of histologically intact clinical specimens of stomach cancer to nude mice: correlation of metastatic sites in mouse and individual patient donors. Int J Cancer 53: 608-612, 1993.

16 Hiroshima $\mathrm{Y}$, Zhang $\mathrm{Y}$, Zhang $\mathrm{N}$, Uehara $\mathrm{F}$, Maawy A, Murakami T, Mii S, Yamamoto M, Miwa S, Yano S, Momiyama M, Mori R, Matsuyama R, Chishima T, Tanaka K, Ichikawa Y, Bouvet M, Endo I and Hoffman RM: Patientderived orthotopic xenograft (PDOX) nude mouse model of soft-tissue sarcoma more closely mimics the patient behavior in contrast to the subcutaneous ectopic model. Anticancer Res 35: 697-701, 2015. 
17 Hiroshima Y, Zhao M, Zhang Y, Zhang N, Maawy A, Murakami T, Mii S, Uehara F, Yamamoto M, Miwa S, Yano S, Momiyama M, Mori R, Matsuyama R, Chishima T, Tanaka K, Ichikawa Y, Bouvet M, Endo I and Hoffman RM: Tumor-targeting Salmonella typhimurium A1-R arrests a chemo-resistant patient soft-tissue sarcoma in nude mice. PLOS ONE 10: e0134324, 2015.

18 Murakami T, DeLong J, Eilber FC, Zhao M, Zhang Y, Zhang N, Singh A, Russell T, Deng S, Reynoso J, Quan C, Hiroshima Y, Matsuyama R, Chishima T, Tanaka K, Bouvet M, Chawla S, Endo I and Hoffman RM: Tumor-targeting Salmonella typhimurium A1-R in combination with doxorubicin eradicate soft tissue sarcoma in a patient-derived orthotopic xenograft PDOX model. Oncotarget 7: 12783-12790, 2016.

19 Kiyuna T, Murakami T, Tome Y, Kawaguchi K, Igarashi K, Zhang Y Zhao M, Li Y, Bouvet M, Kanaya F, Singh A, Dry S, Eilber FC and Hoffman RM: High efficacy of tumor-targeting Salmonella typhimurium A1-R on a doxorubicin- and dactolisibresistant follicular dendritic-cell sarcoma in a patient-derived orthotopic xenograft nude mouse model. Oncotarget 7: 3304633054, 2016.

20 Murakami T, Singh AS, Kiyuna T, Dry SM, Li Y, James AW, Igarashi K, Kawaguchi K, DeLong JC, Zhang Y, Hiroshima Y, Russell T, Eckardt MA, Yanagawa J, Federman N, Matsuyama R, Chishima T, Tanaka K, Bouvet M, Endo I, Eilber FC and Hoffman RM: Effective molecular targeting of CDK4/6 and IGF$1 \mathrm{R}$ in a rare FUS-ERG fusion CDKN2A-deletion doxorubicinresistant Ewing's sarcoma patient-derived orthotopic xenograft (PDOX) nude-mouse model. Oncotarget 7: 47556-47564, 2016.
21 Yamamoto M, Zhao M, Hiroshima Y, Zhang Y, Shurell E, Eilber F,C, Bouvet M, Noda M and Hoffman RM: Efficacy of tumortargeting Salmonella typhimurium A1-R on a melanoma patientderived orthotopic xenograft (PDOX) nude-mouse model. PLoS One 11: e0160882, 2016.

22 Hiroshima Y, Zhang Y, Zhao M, Zhang N, Murakami T, Maawy A, Mii S, Uehara F, Yamamoto M, Miwa S, Yano S, Momiyama M, Mori R, Matsuyama R, Chishima T, Tanaka K, Ichikawa Y, Bouvet M, Endo I and Hoffman RM: Tumor-targeting Salmonella typhimurium A1-R in combination with Trastuzumab eradicates HER-2-positive cervical cancer cells in patientderived mouse models. PLOS ONE 10: e0120358, 2015.

23 Rofstad EK, Simonsen TG, Huang R, Andersen LM, Galappathi K, Ellingsen C, Wegner CS, Hauge A and Gaustad JV: Patientderived xenograft models of squamous cell carcinoma of the uterine cervix. Cancer Lett 373: 147-55, 2016.

24 Hoffman RM and Bouvet M: Nanoparticle albumin-boundpaclitaxel: a limited improvement under the current therapeutic paradigm of pancreatic cancer. Expert Opin Pharmacother 16: 943-947, 2015
Received October 26, 2016

Revised December 2, 2016

Accepted December 5, 2016 